\title{
Genetic diversity of the nucleocapsid protein gene of hippeastrum chlorotic ringspot virus from Hymenocallis littoralis in southern China
}

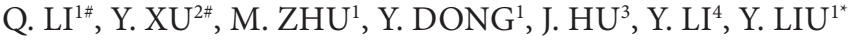

${ }^{1}$ Center of Crop Science Experimental Teaching, College of Agronomy and Biotechnology, Yunnan Agricultural University, Kunming 650201, P. R. China; ${ }^{2}$ College of plant protection, Yunnan Agricultural University, Kunming 650201, P. R. China; ${ }^{3}$ College of Tropical Agriculture and Human Resources, University of Hawaii, Honolulu, HI 96822, USA; ${ }^{4}$ Yunnan Vocational and Technical College of Agriculture, Kunming 650201, P. R. China

Received April 21, 2016; revised July 18, 2016; accepted January 30, 2017

\begin{abstract}
Summary. - Hymenocallis littoralis growing in southern China has been recently extensively damaged by virus-like symptoms of necrosis, chlorosis, and ringspot. Of 44 plant samples collected from Yunnan, Guangxi, Guangdong, and Fujian provinces in southern China, 32 were infected with hippeastrum chlorotic ringspot virus (HCRV). Phylogenetic analysis based on the $N$ gene divided the virus samples into two branches suggesting a geographic distribution attributed to the initial stage of a founder effect. The $N$ gene was under purifying selection pressure and most of the deleterious mutants had been removed. Both the population dynamics and genetic analyses suggested that populations of HCRV in southern China are spreading.
\end{abstract}

Keywords: Hymenocallis littoralis; hippeastrum chlorotic ringspot virus (HCRV); nucleocapsid protein; population expansion; purifying selection pressure; population dynamics

\section{Introduction}

Hymenocallis littoralis (Amaryllidaceae) is a perennial herb (Qing et al., 2007) native to several tropical regions in the Americas. It is cultivated in China as a landscape plant in Yunnan, Guangxi, Guangdong and Fujian provinces. In 2013, a new tospovirus, hippeastrum chlorotic ringspot virus (HCRV), was identified on H. littoralis (Dong et al., 2013; $\mathrm{Xu}$ et al., 2013). Tospovirus is the only genus in the family Bunyaviridae that infects plants. The virus systemically infects Cucumis sativus, Cucurbita moschata, Emilia sonchifolia,

*Corresponding authors. E-mail: liuyating66@163.com; phone: +86-15394978096. ${ }^{*}$ These authors contributed equally to this work.

Abbreviations: $\mathrm{dN}=$ non-synonymous substitutions; $\mathrm{dS}=$ number of synonymous substitutions; HCRV = hippeastrum chlorotic ringspot virus; $\mathrm{H}(\mathrm{s})$ = haplotype(s); $\mathrm{Hd}$ = haplotype diversity; $\mathrm{K}=$ average number of nucleotide differences; $\mathrm{N}=$ nucleocapsid; $\pi=$ average pairwise nucleotide diversity; $\mathrm{S}=$ number of polymorphic sites; TSWV 111= tomato spotted wilt virus
Hippeastrum striatum, H. littoralis, Lactuca sativa, Solanum lycopersicum, Phaseolus vulgaris, Tropaeolum majus, and Vigna unguiculata (Xu et al., 2013). The main symptoms are concentric chlorotic rings, leaf malformation, and localized chlorosis and necrosis. This disease poses a serious threat to landscape plantings.

The whole genome of HCRV contains three RNA segments: S, M and L. The 2,724-nt S RNA segment encodes two proteins, a 444-aa non-structural protein (NSs) that is a genesilencing suppressor, and a 275-aa nucleocapsid protein $(\mathrm{N})$. $\mathrm{N}$ protein is the main viral ribonucleoprotein (Richmond et al., 1998), is responsible for virus movement (Zhang et al., 2012) and is involved in homotypic interactions (Uhrig et al., 1999) in tomato spotted wilt virus (TSWV). The 4,741-nt M RNA also encodes two proteins: a 309-aa non-structural protein (NSm) that functions in cell-to-cell virus movement in plants, and a 1,130-aa glycoprotein precursor $(\mathrm{Gn} / \mathrm{Gc})(\mathrm{Xu}$ et al., 2013). The 8,909-nt L RNA encodes a 2,873-aa RNAdependent RNA polymerase (RdRp) (Xu et al., 2014).

Since 2012, the incidence of tospovirus-like symptoms on $H$. littoralis in southern China has increased. We collected 
plant samples from Yunnan, Guangxi, Guangdong and Fujian provinces (Fig. 1) and used a molecular population genetics approach to study the structure of HCRV in these areas.

\section{Materials and Methods}

Sample collection and preservation. We collected 44 samples of $H$. littoralis with typical symptoms of tospovirus infection between 2012 and 2013. Leaf symptoms included chlorotic mottling, concentric chlorotic rings, and marginal necrosis (Supplementary Fig.1). Lesions from infected leaves were placed in $1.5-\mathrm{ml}$ centrifuge tubes and stored at $-80^{\circ} \mathrm{C}$. We used RT-PCR with tospovirusspecific primers (Supplementary Table 1) and identified HCRV in all symptomatic plant samples.

Total RNA isolation and cDNA synthesis. Approximately $100 \mathrm{mg}$ of symptomatic tissue was collected from each plant sample and total RNA isolated using a TransZol Plant Kit (TransGen Biotech, Beijing, China) according to manufacturer's instructions. Total RNA was reverse transcribed as a template to synthesize first-strand cDNA using a PrimeScript ${ }^{\mathrm{TM}}$ II 1st strand cDNA Synthesis Kit (TaKaRa, Dalian, China) and random primers.

Sample identification. We used RT-PCR with tospovirus-specific primers (Supplementary Table 1 ) and identified HCRV in all symptomatic plant samples. The PCR system contained 0.25-0.5 $\mu \mathrm{l}$ cDNA (less than $100 \mathrm{ng}), 0.5 \mu \mathrm{l}$ forward and reverse primers $(10 \mu \mathrm{mol} / \mathrm{l})$, $5 \mu \mathrm{l} 2 \times$ TransTaq High Fidelity (HiFi) PCR SuperMix II (TransGen Biotech, Beijing, China), and $\mathrm{ddH}_{2} \mathrm{O}$ to $10 \mu \mathrm{l}$. PCR reaction conditions were: initial degeneration at $94^{\circ} \mathrm{C}$ for $5 \mathrm{~min} ; 35$ cycles at $94^{\circ} \mathrm{C}$ for $30 \mathrm{~s}, 55^{\circ} \mathrm{C}$ for $30 \mathrm{~s}$, and $72^{\circ} \mathrm{C}$ for $1 \mathrm{~min}$, with a final extension at $72^{\circ} \mathrm{C}$ for $10 \mathrm{~min}$. PCR products $(5 \mu \mathrm{l})$ were detected using $1.5 \%$ agarose gel electrophoresis. PCR fragments were gel purified using a multi-functional DNA purification recycling kit (centrifugal columns) (BioTeke Corporation, Beijing, China). The fragments were ligated into the pEASY-T1 vector (TransGen Biotech, Beijing, China) and transformed into Escherichia coli DH5a-competent cells. Positive colonies were selected using blue-white screening. After colony validation by PCR, the samples were sequenced by Beijing Genomics Institute (BGI, Shenzhen, China) and analyzed with the Basic local alignment search tool (Altschul et al., 1990).
$N$ gene amplifying, cloning and sequencing. The specific primers NP2-F (5'-CACAATAAACACACAAACA-3') and NP2-R (5'-CTTCCTAAGTAAACACCA T-3') were used to amplify the full-length HCRV $N$ gene. PCR experiments were conducted as described above.

Recombination detection and phylogenetic tree construction. $N$ gene sequences for HCRV isolates HLS1-2 (Acc. No. JX833564) and HCRV-ZDH-2007 (accession number KC290943) were downloaded from NCBI (http://www.ncbi.nlm.nih.gov/) and analyzed together with the identified HCRV sequences. Recombination events were detected with the Recombination Detection Program, version 3.44 (Martin et al., 2010). Phylogenetic trees were constructed using the maximum likelihood method and MEGA 6.0 software, version 6.0 (The Biodesign Institute, Tempe, AZ, USA) with each branch supported by a bootstrap of 1,000 replicates (Tamura et al., 2011). Identification among the different isolates was calculated using Clustal X (Larkin et al., 2007).

Genetic diversity and population dynamics analyses. Haplotype diversity (Hd), average number of haplotypes (h), average pairwise nucleotide diversity $(\pi)$, average number of nucleotide differences (K) and number of polymorphic sites (S) were estimated using DnaSP, version 5.10.00 (Universitat de Barcelona, Diagonal, Barcelona, Spain) (Tajima, 1983). Previous population dynamics of HCRV strains was analyzed from the $N$ gene sequence using the Bayesian skyline plot in the program Beast, version 1.8.2 (http:// beast.bio.ed.ac.uk/). Bayesian skyline plot uses a Markov Chain Monte Carlo procedure to sample the distribution of generalized skyline plots. The effective population through time was generated and combined with the plot.

Selection pressure and positive selection site identification. We used DnaSP, version 5.10.00, (Tajima, 1983) to conduct interspecies neutrality tests using three site-frequency spectrum-based methods: Tajima's D (Tajima, 1989) test, and Fu and Li's D (Fu and $\mathrm{Li}, 1993$ ) and F tests. Six selection-pressure models for the coding regions of amino acids were calculated using the codeml program of the Phylogenetic Analysis by Maximum Likelihood (PAML) software package, version 1.2 (UCL, London, England) (Yang, 2007). The models were: M0 (one $\omega$ ), M1a (nearly neutral), M2a (positive selection), M3 (discrete), M7 (nearly neutral with the beta distribution approximating $\omega$ variation),

Table 1. Summary of $N$ gene diversity of hippeastrum chlorotic ringspot virus isolates from Hymenocallis littoralis in southern China

\begin{tabular}{ccccccccc}
\hline Gene & $\begin{array}{c}\text { Geographical } \\
\text { population }\end{array}$ & Tajima's D & Fu and Li's D & Fu and Li's F & Hd $^{1}$ & H $^{2}$ & $\boldsymbol{\pi}^{3}$ & $\mathbf{K}^{4}$ \\
\hline$N$ & $\mathrm{YN}^{6}$ & -0.38374 & -1.06900 & -1.06900 & 0.945 & 9 & 0.00529 & 4.364 \\
& $\mathrm{GX}^{7}$ & -0.77880 & -0.88379 & -0.95219 & 0.964 & 7 & 0.00394 & 3.250 \\
& $\mathrm{GD}^{8}$ & -1.30883 & -1.36444 & -1.50220 & 1.000 & 8 & 0.00593 & 4.893 \\
& $\mathrm{FJ}^{9}$ & 0.49429 & 1.00386 & 1.00386 & 0.952 & 6 & 0.01720 & 14.190 \\
\hline
\end{tabular}

${ }^{1}$ Haplotype diversity; ${ }^{2}$ Number of haplotypes; ${ }^{3}$ Average pairwise nucleotide diversity; ${ }^{4}$ Average number of nucleotide differences; ${ }^{5} \mathrm{Number}$ of polymorphic sites; ${ }^{6}$ Isolates collected from Yunnan Province, China; ${ }^{7}$ Isolates collected from Guangxi Province, China; ${ }^{8}$ Isolates collected from Guangdong Province, China; ${ }^{9}$ Isolates collected from Fujian Province, China. 
Table 2. Parameter estimations for 6 selection pressure models for the $N$ gene of 32 hippeastrum chlorotic ringspot virus isolates from Hymenocallis littoralis in southern China

\begin{tabular}{|c|c|c|c|c|c|}
\hline Gene & Models & Parameter Estimates & $\ln L^{1}$ & $2 \Delta \mathbf{L}^{4}$ & NEB analysis ${ }^{5}$ \\
\hline \multirow[t]{12}{*}{$N$} & M0 & $\omega^{2}=0.26198$ & -1503.358217 & 0 & None \\
\hline & M3 & $\mathrm{p} 0=0.20776, \omega 0=0.27451$ & -1503.358217 & & Not allowed \\
\hline & & $\mathrm{p} 1=0.44351, \omega 1=0.27451$ & & & \\
\hline & & $\mathrm{p} 2=0.34873, \omega 2=0.27451$ & & & \\
\hline & M1a & $\mathrm{p} 0^{3}=0.99999, \omega 0=0.27450$ & -1503.358263 & 0 & None \\
\hline & & $\mathrm{p} 1=0.00001, \omega 1=1.00000$ & & & \\
\hline & M2a & $\mathrm{p} 0=1.00000, \omega 0=0.27451$ & -1503.358217 & & Not allowed \\
\hline & & $\mathrm{p} 1=0.00000, \omega 1=1.00000$ & & & \\
\hline & & $\mathrm{p} 2=0.00000, \omega 2=1.00000$ & & & \\
\hline & M7 & $\mathrm{p}=37.58955, \mathrm{q}=99.00000$ & -1503.371733 & 0 & None \\
\hline & M8 & $\mathrm{p} 0=0.99999, \mathrm{p}=37.58870$ & -1503.371756 & & Not allowed \\
\hline & & $\begin{array}{l}q=99.00000, p 1=0.00001 \\
\omega=1.00000\end{array}$ & & & \\
\hline
\end{tabular}

${ }^{1}$ Log-likelihood values; ${ }^{2}$ Ratio of the number of non-synonymous substitutions per non-synonymous site to the number of synonymous substitutions per synonymous site $(\mathrm{dN} / \mathrm{dS}) ;{ }^{3} \mathrm{p}^{*}$ stands for the number $\left.{ }^{*}\right)$ of parameters in different models; ${ }^{4} \mathrm{In} \mathrm{M} 0$ vs $\mathrm{M} 3 \mathrm{when} \mathrm{df}=4, \mathrm{P}=5 \%, \chi^{2}=9.49$. In M1a vs M2a and $\mathrm{M} 7$ vs $\mathrm{M} 8$, when $\mathrm{df}=2$ and $\mathrm{P}=5 \%, \chi^{2}=5.99 ;{ }^{5}$ Naive Empirical Bayes (NEB) analysis, positively selected sites include those with $\mathrm{P}<95 \%$.

and M8 (positive selection with the beta distribution approximating $\omega$ variation). The symbol " $\omega$ " is the ratio of the number of non-synonymous substitutions per non-synonymous site to the number of synonymous substitutions per synonymous site. The Likelihood Ratio Test was used to judge which modes were accepted between M1 and M3, M1a and M2a, and M7 and M8 (Yang et al., 2000).

\section{Results}

RT-PCR amplification, cloning and sequencing

Among 44 samples of $H$. littoralis from eight cities (Fig. 1) tested using RT-PCR, 32 were infected by HCRV only, one

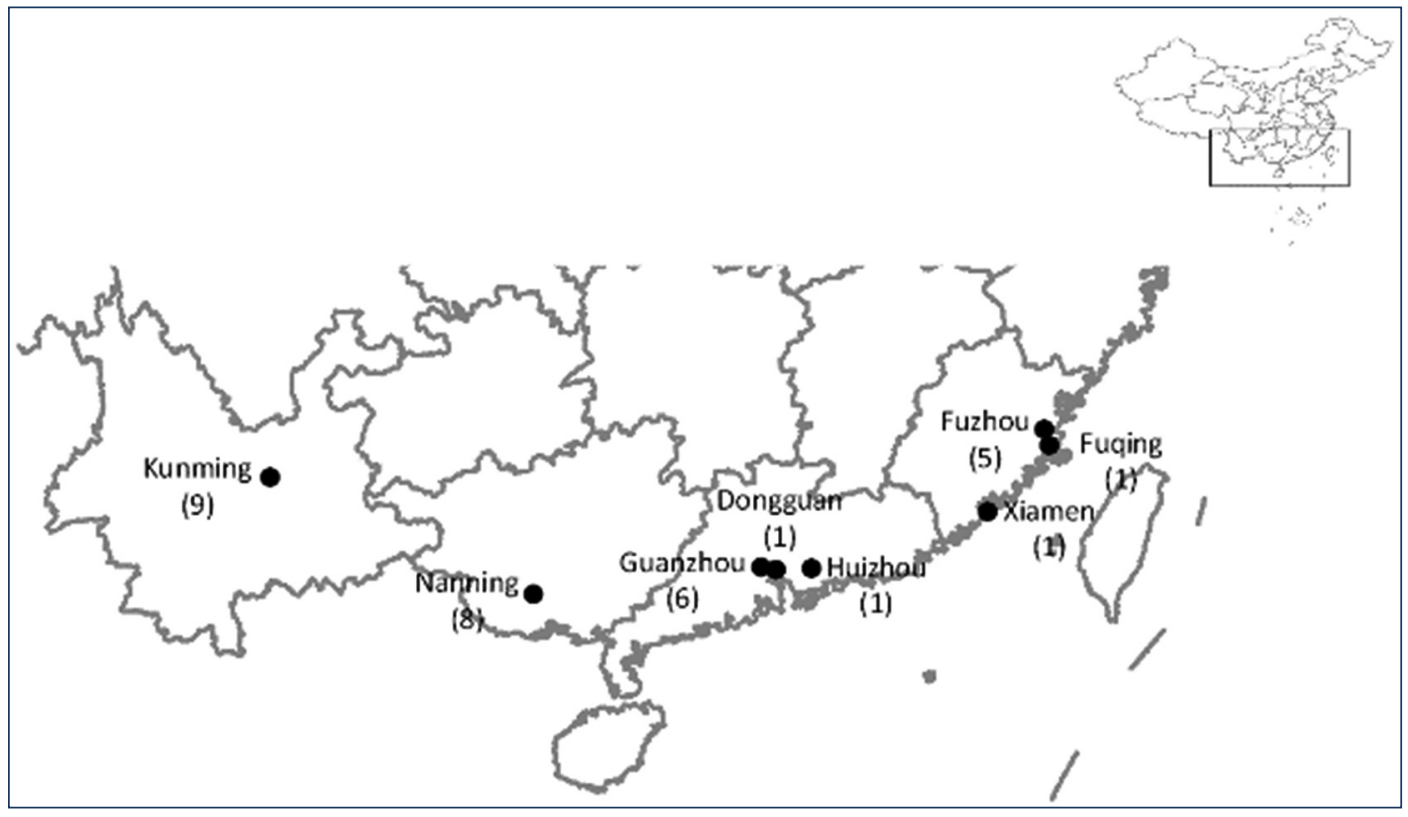

Fig. 1

Location of the eight cities, from which plant samples were collected

Kunming in Yunnan Province; Nanning in Guangxi Province; Guangzhou, Dongguan and Huizhou in Guangxi Province; and Xiamen, Fuqing and Fuzhou in Fujian Province. The numbers in parentheses indicate the number of samples collected from each city. 


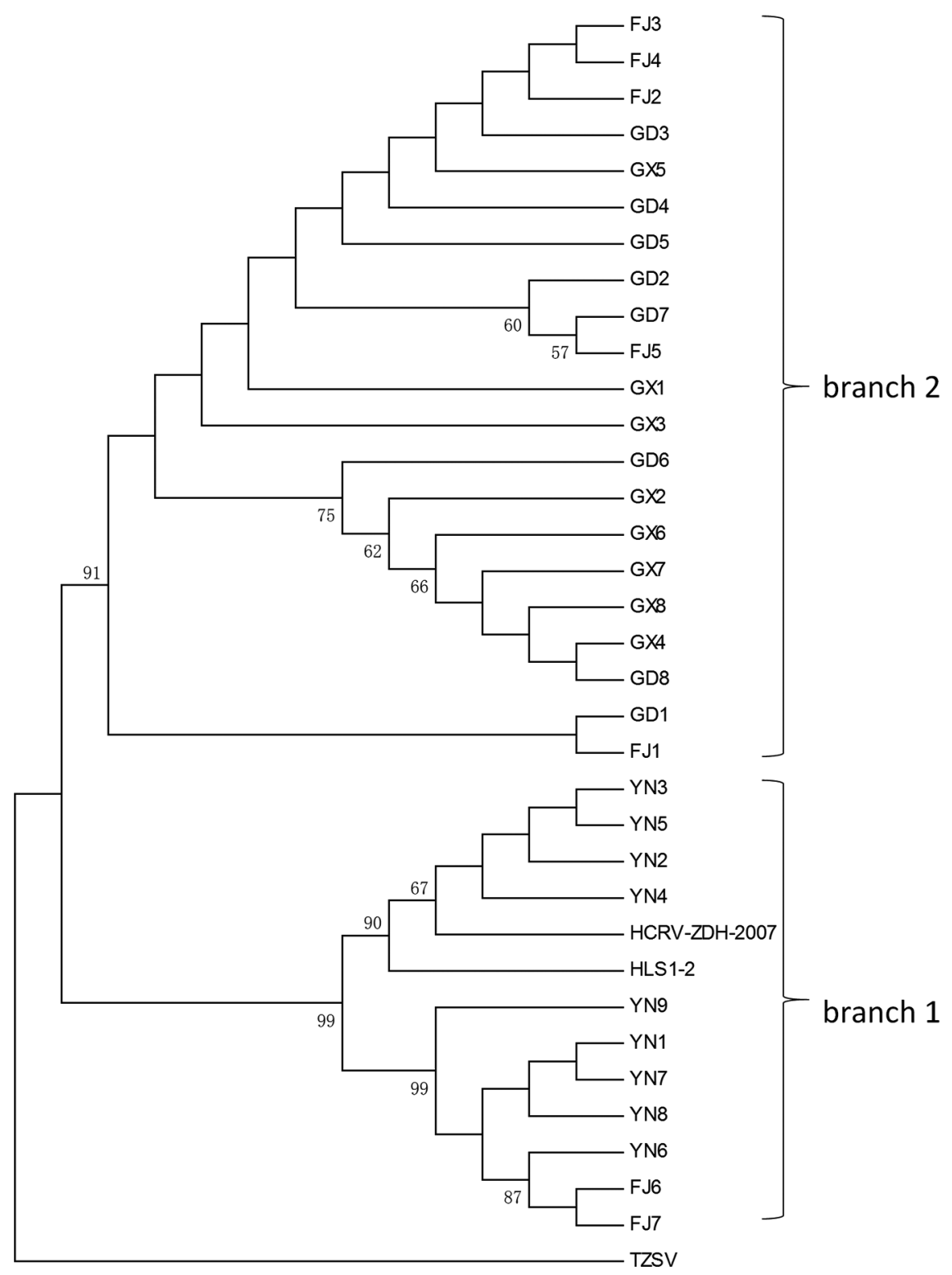

Fig. 2

Phylogenetic tree based on nucleotide sequences of the $N$ gene of hippeastrum chlorotic ringspot virus isolates from Hymenocallis littoralis in southern China

HLS1-2 (Acc. No. JX833564) and HCRV-ZDH-2007 (Acc. No. KC290943) are reference sequences. TZSV (Acc. No. DQ462163) is the outgroup. YN = Yunnan Province; FJ = Fujian Province; GX = Guangxi Province; and GD indicates Guangdong Province. The tree was constructed by the maximum likelihood method with 1,000 bootstrap replicates using MEGA 6.0 software.

by TSWV and HCRV, and one was infected by calla lily chlorotic spot virus (CCSV) and tomato zonate spot virus (TZSV). The full-length sequence of the HCRV $N$ gene of the 32 isolates was $825 \mathrm{nt}$. The sequences were submitted to NCBI GenBank with Acc. Nos. KR361549 to KR361580 (Supplementary Table 2).

\section{Phylogenetic analysis}

No recombination events were detected in the $N$ gene of these HCRV isolates using the Recombination Detection Program. Based on these $32 \mathrm{~N}$ gene sequences and the 2 reference sequences HLS1-2 and HCRV-ZDH-2007, a phy- 
logenetic tree was constructed (Fig. 2). The results showed a mixed distribution with all isolates from Yunnan province plus two isolates from Fujian, FJ6 and FJ7, clustered in one branch. Other isolates from Guangxi and Guangdong Provinces and most of the isolates from Fujian Province were clustered in another branch. Some of the clades, however, suggested a geographic origin of isolates. For example, isolates from the Yunnan Province clustered in a single clade (Fig. 2). The similarity analyses among isolates suggested similar results (Supplementary Table 3).

\section{Analysis of genetic diversity within populations}

The genetic diversity among isolates from different provinces was separated and evaluated. We verified that the diversity of HCRV was increasing by analyzing nucleotide and haplotype diversities (Grant and Bowen, 1998). Our results (Table 1) detected 30 haplotypes: 9 in Yunnan Province, 8 in Guangdong Province, 7 in Guangxi Province, and 6 in Fujian Province. The estimated values of the haplotype diversities of the isolates from each province were from 0.945 to 1.000 . The estimated values of the nucleotide diversities were between 0.00394 (Guangxi Province) and 0.01720 (Fujian Province). The average number of nucleotide differences (K) was between 3.250 (Guangxi Province) and 14.190 (Fujian Province). The number of polymorphic sites was between 9 (Guangxi Province) and 32 (Fujian Province).
These results indicated that the genetic diversity within the HCRV population in 2012-2013 was high.

\section{Analysis of HCRV population dynamics}

Population dynamics was analyzed using a Bayesian skyline plot based on $N$ gene sequences from the HCRV isolates. According to the plot analysis, the diversity of the HCRV population remained stable or at a low level before 2008, but its size increased after 2008 and reached a high level in 2012-2013 (Fig. 3).

\section{Determination of selection pressure}

Tajima's D test and Fu and Li's D and F tests detected nucleotide polymorphisms in the genome. Test values for the $N$ gene from the Yunnan, Guangxi and Guangdong isolates were negative among geographic locations and isolates from Fujian were greater than 0 (Table 1). However, the differences were not statistically significant $(\mathrm{P}>0.10)$.

We calculated the parameters of the M0, M1a, M2a, M3, M7 and M8 models using the codeml program in PAML based on the sequence of the HCRV $N$ gene. According to the related parameters of the M0 vs. M3, M1a vs. M2a, and M7 vs. M8 models, the $\ln L$ values of the positive selection models (M2, M3 and M8) were significantly greater than the values in the corresponding null hypothesis models (Chen

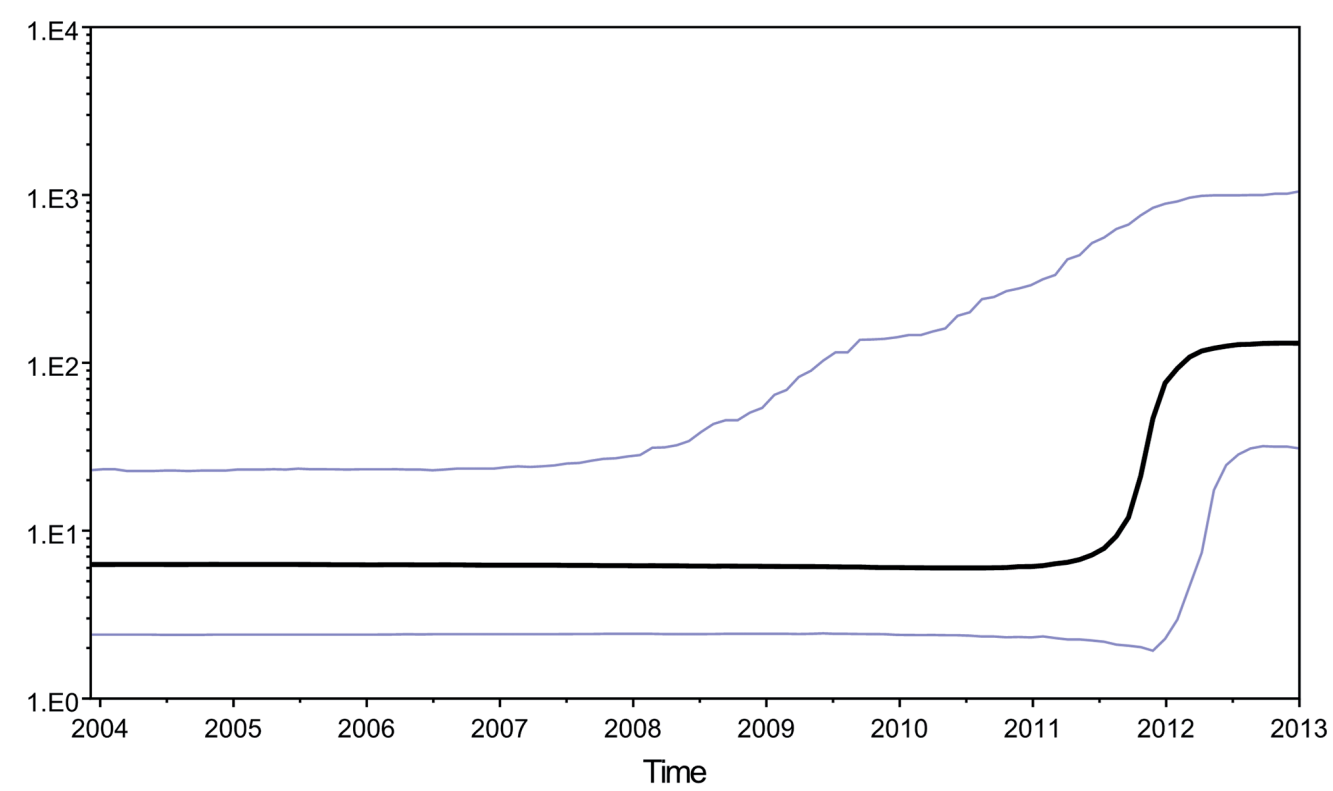

Fig. 3

Bayesian skyline plot of HCRV

The black line represents the number of infections estimated by the $N$ gene and the region between blue lines represent the $N$ gene at a $95 \%$ highest probability density confidence limit. 
and Chen, 2014). The $2 \Delta \operatorname{lnL}$ values of models M0 vs. M3 were lower than 9.49, so model M3 was discarded. However, the $2 \Delta \operatorname{lnL}$ of M1a vs. M2a and M7 vs. M8 were lower than 5.99, so models M2 and M8 were rejected. These results suggested that most of the HCRV $N$-gene sites underwent purifying selection pressure.

\section{Discussion}

Eleven Tospovirus species have been reported in China (Chen et al., 2007; Ding et al., 2007; Dong et al., 2008, 2010; Gu et al., 2012; Liu et al., 2010, 2012; Meng et al., 2013; Rao et al., 2013; Xu et al., 2013; Cheng et al., 2014). Of these, tomato zonate spot virus (Dong et al., 2008), HCRV (Xu et al., 2013, 2014) Mulberry vein banding virus (Meng et al., 2013) and tomato necrotic spot virus (Cheng et al., 2014) were first identified on mainland China. About $73 \%(32 / 44)$ of the H. littoralis samples with tospovirus-like symptoms we collected in southern China tested positive for HCRV.

Tsompana and others (Tsompana et al., 2005) studied the molecular population genetics of the TSWV genome and found that its geographic structure may have been attributed to founder effects. A founder effect is the loss of genetic variation that occurs when a new population is established by a small number of individuals from a larger population (Templeton, 1980). Founder mutations begin when changes in the DNA are passed down to other generations. The ultimate example of the founder effect in a phylogenetic tree occurs when its structure matches the organism's geographic distribution (Templeton, 1980). The structure of the phylogenetic tree in this study suggested a geographic distribution of HCRV. Some of the branches were mixed, and these inconsistencies in the tree's structure may have been caused by unknown events such as the introduction of infected $H$. littoralis from another area. Similar to the research on TSWV, some geographically related isolates of HCRV may be in the initial stages of the founder effect. Results of the selection analysis suggested that the HCRV $\mathrm{N}$ gene has undergone a purifying selection pressure.

We detected a neutral equilibrium among the $N$ genes of HCRV isolates from each province, with a high haplotype diversity and low nucleotide diversity. Tajima's D test and $\mathrm{Fu}$ and Li"s D and F tests of isolates from Yunnan, Guangxi and Guangdong provinces had negative values. This may have been due to background selection, genetic hitchhiking, or a population expansion effect. Generally, background selection and genetic hitchhiking affect a relatively small portion of genome sites. Since multiple sites produced negative values, however, this may indicate a population expansion among the collected isolates (Tajima, 1983; Hey and Harris, 1999).
Our analysis of the population dynamics of HCRV in the southern provinces of China suggested that the spread of the virus coincides with an increase in the building of cities. This construction was accompanied by landscaping projects and green areas, in which $H$. littoralis was a popular landscape plant. These infected plants are now a reservoir of the disease and threaten landscape plantings and agriculture.

Acknowledgements. This work was supported by the National Science Foundation of China (No. 31471828, 31260451 and 30960224), the Key Project of the New Product Development Plan of Yunnan Province (2014BB005), and the Academic Award for Up-andcoming Doctoral Candidates of Yunnan Province.

Supplementary information is available in the online version of the paper.

\section{References}

Altschul SF, Gish W, Miller W, Myers EW, Lipman DJ (1990): Basic local alignment search tool. J. Mol. Biol. 215, 403-410. https://doi.org/10.1016/S0022-2836(05)80360-2

Chen K, Xu Z, Yan L, Wang G (2007): Characterization of a new strain of Capsicum chlorosis virus from peanut (Arachis hypogaea L.) in China. J. Phytopathol. 155, 178-181. https://doi.org/10.1111/j.1439-0434.2007.01217.x

Chen Y, Chen YF (2014): Evidence of selection pressures of neuraminidase gene (NA) of influenza A virus subtype H5N1 on different hosts in Guangxi Province of China. Saudi J. Biol. Sci. 21, 179-183. https://doi.org/10.1016/j. sjbs.2013.09.009

Cheng Y, Zheng Y, Tai C, Yen J, Chen Y, Jan F (2014): Identification, characterisation and detection of a new tospovirus on sweet pepper. Ann. Appl. Biol. 164(1), 107-115. https:// doi.org/10.1111/aab.12084

Ding M, Luo Y, Fang Q, Zhang Z, Zhao Z (2007): First report of Groundnut yellow spot virus infecting Capsicum annuum in China. J. Plant Pathol. 305-305.

Dong JH, Cheng, XF, Yin, YY, Fang Q, Ding M, Li TT, Zhang LZ, Su XX, McBeath, JH, Zhang, ZK (2008): Characterization of tomato zonate spot virus, a new tospovirus in China. Arch. Virol. 153, 855-864. https://doi.org/10.1007/ $\underline{\text { s00705-008-0054-5 }}$

Dong J, Yin Y, Fang Q, Mcbeath J, Zhang Z (2013): A new tospovirus causing chlorotic ringspot on Hippeastrum sp. in China. Virus Genes 46, 567-570. https://doi.org/10.1007/ $\underline{\text { s11262-012-0873-Z }}$

Dong J, Yin Y, Xu X, Duan Y, Zhang Z (2010): First report of Tomato spotted wilt virus in tomato and tobacco in China. J. Plant Pathol. S121-S121.

Fu YX, Li WH (1993): Statistical tests of neutrality of mutations. Genetics 133, 693-709.

Grant W, Bowen B (1998): Shallow population histories in deep evolutionary lineages of marine fishes: insights from sardines and anchovies and lessons for conservation. J. Hered. 89, 415-426. https://doi.org/10.1093/jhered/89.5.415 
Gu Q, Wu H, Chen H, Zhang X, Wu M, Wang D, Peng B, Kong X, Liu T (2012): Melon yellow spot virus identified in China for the first time. New Disease Reports 25, 7. https://doi. org/10.5197/j.2044-0588.2012.025.007

Hey J, Harris E (1999): Population bottlenecks and patterns of human polymorphism. Mol. Biol. Evol. 16, 1423-1426. https://doi.org/10.1093/oxfordjournals.molbev.a026054

Kryazhimskiy S, Plotkin JB (2008): The population genetics of dN/ dS. PLoS Genetics 4, e1000304. https://doi.org/10.1371/ journal.pgen.1000304

Larkin MA, Blackshields G, Brown N, Chenna R, McGettigan PA, McWilliam H, Valentin F, Wallace IM, Wilm A, Lopez R (2007): Clustal W and Clustal X version 2.0. Bioinformatics 23, 2947-2948. https://doi.org/10.1093/ bioinformatics/btm404

Lian S, Lee JS, Cho WK, Yu J, Kim MK, Choi HS, Kim KH (2013): Phylogenetic and recombination analysis of tomato spotted wilt virus. Plos One 8, e63380. https://doi.org/10.1371/ journal.pone. 0063380

Liu Y, Lu X, Zhi L, Zheng Y, Chen X, Xu Y, Wu F, Li Y (2012): Calla lily chlorotic spot virus from spider lily (Hymenocallis litteralis) and tobacco (Nicotiana tabacum) in the southwest of China. J. Phytopathol. 160, 201-205. https://doi. org/10.1111/j.1439-0434.2011.01873.x

Liu Y, Zheng Y, Li Y, Li Z (2010): First report of Impatiens necrotic spot virus on spiderlily in China. Plant Dis. 94, 484-484. https://doi.org/10.1094/PDIS-94-4-0484C

Martin DP, Lemey P, Lott M, Moulton V, Posada D, Lefeuvre P (2010): RDP3: a flexible and fast computer program for analyzing recombination. Bioinformatics 26, 2462-2463. https://doi.org/10.1093/bioinformatics/btq467

Meng J, Liu P, Zou C, Wang Z, Liao Y, Cai J, Qin B, Chen B (2013): First report of a Tospovirus in mulberry. Plant Dis. 97, 1001. https://doi.org/10.1094/PDIS-08-12-0792-PDN

Qing L, Juying X, Xiangnan L (2007): Cultivation and propagation of Lycoris. Journal of Anhui Agricultural Sciences 35, 10678.

Rao X, Wu Z, Li Y (2013): Complete genome sequence of a Watermelon silver mottle virus isolate from China. Virus Genes 46, 576-580. https://doi.org/10.1007/s11262-013 -0885-3

Richmond K, Chenault K, Sherwood J, German T (1998): Characterization of the nucleic acid binding properties of tomato spotted wilt virus nucleocapsid protein. Virology 248, 6-11. https://doi.org/10.1006/viro.1998.9223

Rozas J, Rozas R (1995): DnaSP, DNA sequence polymorphism: an interactive program for estimating population genetics parameters from DNA sequence data. Computer applications in the biosciences: CABIOS 11, 621-625. https:// doi.org/10.1093/bioinformatics/11.6.621

Tajima F (1983): Evolutionary relationship of DNA sequences in finite populations. Genetics 105, 437-460.
Tajima F (1989): Statistical method for testing the neutral mutation hypothesis by DNA polymorphism. Genetics 123 , 585-595.

Tamura K, Peterson D, Peterson N, Stecher G, Nei M, Kumar S (2011): MEGA5: molecular evolutionary genetics analysis using maximum likelihood, evolutionary distance, and maximum parsimony methods. Mol. Biol. Evol. 28, 2731-2739. https://doi.org/10.1093/molbev/msr121

Templeton AR (1980): The theory of speciation via the founder principle. Genetics 94, 1011-1038.

Tsompana M, Abad J, Purugganan M, Moyer J (2005): The molecular population genetics of the Tomato spotted wilt virus (TSWV) genome. Mol. Ecol. 14, 53-66. https://doi. org/10.1111/j.1365-294X.2004.02392.X

Uhrig J, Soellick T, Minke C, Philipp C, Kellmann J, Schreier P (1999): Homotypic interaction and multimerization of nucleocapsid protein of tomato spotted wilt tospovirus: identification and characterization of two interacting domains. Proc. Natl. Acad. Sci. USA 96, 55-60. https:// doi.org/10.1073/pnas.96.1.55

Webster CG, Reitz SR, Perry KL, Adkins S (2011): A natural M RNA reassortant arising from two species of plant-and insect-infecting bunyaviruses and comparison of its sequence and biological properties to parental species. Virology 413, 216-225. https://doi.org/10.1016/j. virol.2011.02.011

Whitfield AE, Ullman DE, German TL (2005): Tospovirus-thrips interactions. Annu. Rev. Phytopathol. 43, 459-489. https://doi.org/10.1146/annurev.phyto.43.040204.140017

Xu Y, Lou SG, Li QF, Hu Q, Sun LP, Li ZY, Li YZ, Liu YT (2014): Molecular characterization of the hippeastrum chlorotic ringspot virus L segment and its protein. Arch. Virol. 2805-28077. https://doi.org/10.1007/s00705-014 $-2100-9$

Xu Y, Lou SG, Li XL, Zheng YX, Wang WC, Liu YT (2013): The complete $S$ RNA and M RNA nucleotide sequences of a hippeastrum chlorotic ringspot virus (HCRV) isolate from Hymenocallis littoralis (Jacq.) Salisb in China. Arch. Virol. 158, 2597-2601. https://doi.org/10.1007/ s00705-013-1756-x

Yang Z (2007): PAML 4: phylogenetic analysis by maximum likelihood. Mol. Biol. Evol. 24, 1586-1591. https://doi. org $/ 10.1093 / \mathrm{molbev} / \mathrm{msm} 088$

Yang Z, Nielsen R, Goldman N, Pedersen A-MK (2000): Codonsubstitution models for heterogeneous selection pressure at amino acid sites. Genetics 155, 431-449.

Zhang Y, Zhang C, Li W (2012): The nucleocapsid protein of an enveloped plant virus, Tomato spotted wilt virus, facilitates long-distance movement of Tobacco mosaic virus hybrids. Virus Res. 163, 246-253. https://doi.org/10.1016/j. virusres.2011.10.006 